\title{
Research on Urban Innovative Talents Training Strategies based on the Chinese University Education System
}

\author{
Lan $\mathrm{Ma}^{1, \text { a }}$ \\ ${ }^{1}$ Art and Design College, Lanzhou Jiaotong University, Lanzhou, Gansu, 730000 \\ ${ }^{a}$ email
}

Keywords: Innovation Talents Training Strategies, University Education System

\begin{abstract}
How to adapt to the development of contemporary society, changes in teaching methods, to cultivate the scientific research ability has a profound professional knowledge and expertise, but also have high-quality talent is worth every educator thought. This article explain how to cultivate innovative talents in the current education system, namely: the students' interest in learning, students are encouraged to be creative, to strengthen the faculty, strengthen innovation curriculum, curriculum system clear the value of innovation, scientific and rational design courses, build a new model of innovative talents.
\end{abstract}

\section{Introduction}

Review the history of higher education, it is easy to see, the university in its emergence and development process, formed a relatively complete innovation system, effectively promote the development of a culture of innovation. With the growth of the power of human innovation, universities, governments and industry jointly open up a new era. Innovative culture of the times, and to walk quietly in the center of the modern knowledge economy and society, University coupling social interaction among human social development in the status and mission of growing importance, and to continue to achieve its own paradigm shift, university culture essence of human culture and shaping, university innovation culture is fertile ground for cultivating innovative talents, plays a fundamental, critical and fundamental role in nurturing creative talents, contemporary Chinese personnel training reforms need to focus on innovation culture, through personnel training paradigm shift, the full realization of the functions of the modern university, allowing universities to always lead the social and cultural progress.

Who is the subject of innovation, technological innovation is inseparable from the innovative talents. What innovative talents? In short, innovative and quality achieved through innovative practice innovations person. Specifically, the innovative talent typically have strong sense of innovation, creativity and innovation, not the status quo, it is possible to forge ahead, the courage to challenge the risk, be good to ask probing questions and thoughtful manner with a unique application of knowledge to deal with solve problems, and ultimately "discovering, inventing, creating and advancing", get innovative achievements. It has a sense of innovation, innovative spirit and ability to be a new era of innovative talents most fundamental requirement is a concentrated expression of talents' creative quality. Primitive sense of innovation is innovation, the spirit of innovation and the ability to innovate the foundation and prerequisite. Important internal factors affect the spirit of innovation and development of the ability to generate innovation and subjective conditions. And enhance innovation ability is enhanced sense of innovation and wealth of the most powerful reason to support innovative.

\section{Innovative Talents and Quality Characteristics}

The comprehensive feature innovative talents can be summarized as the following aspects:

Comprising at least two meanings: For example, to treat a problem, he will ask: "Why not find a new method (ideas) to solve?" "Why not invent a new technology (equipment) to deal with this issue," the second is capable of? seemingly mundane things perceive some strange, unusual things, such as can be found in the question implies a different examination questions. Creativity comes 
from rich association and rich association and from the observation. Therefore, the scientific method of observation and the ability to observe the formation of ideas and even has a great significance in the whole innovation process.

Under other conditions the same, innovative talents to break through traditional thinking set, thinking and analysis on the problem from a variety of angles, multiple levels, and according to different information to modify their understanding of the issues, with a strong adaptation sex. In the same other conditions, at the same time to form more ideas or more ideas, and often able to make unusual and because they can be accepted, recognized point of view.

Innovative talents in general has a strong personality and independence; there is a strong achievement motivation, look forward to its success; mental health, but the anxiety level may be higher than others; or something of a very focused, strong perseverance; can tolerate errors, not harsh; not to simplify complex issues, issues of tolerance is not clear or fuzzy things exist; generally less interested in the details and facts, but something abstract and generalized knowledge of interest rich; social skills and interpersonal skills may not be prominent; gender awareness and the role is not obvious, is not confined to fixed gender program. The healthy and stable non-intellectual factors in the innovation process can play a dynamic, orientation, maintain, and strengthen the role of innovative activities continue to strengthen the motivation and the need to stimulate innovation and enthusiasm, the formation of innovation.

\section{Creative Talents Train Strategies}

Interest, even the best teacher can not teach the practice, so the teacher must be conscious while teaching students interest in learning, students' interest in learning once you have, you have motivation to learn naturally, and energy in learning music lotus, busy but not tired, learning efficiency can be improved effectively, and even play a multiplier effect, many talented inspiration often comes from their interest. The general problem is the current lack of interest in the presence of students, students learning no curiosity, lack of motivation inside of the class is not interested in this, teachers should be teaching method to make corresponding adjustments to adapt to the current rapid development of society, transform education, and the inner motivation of students, to stimulate their desire to learn.

Students are encouraged to be creative. In the process of teaching teachers must encourage students to dare to break through textbooks, breaking his own teacher, the progress of science is that inheritance results of previous studies on the basis of suspicion and can negate their predecessors, continue to make their own new ideas, improve their predecessors the results, which is innovation. With the development of the times, the rapid technological innovation, talent has become an important manifestation of the country's competitiveness in this era, there is a saying that goes: What is the most important in the 21st century. Talent. The training of personnel is required from the students start and therefore, to develop students ability to innovate has become an important task in this day and age of the teacher. Cultivate innovative talents necessary to abandon the old teaching philosophy to promote new and innovative teaching concepts. In today's society, in the face of increasingly fierce competition in the status quo, many teachers the pursuit of highly educated reap good career as a pursue that formed a single teaching method, teaching content obsolete, educational philosophy of traditional teaching methods, students are also dead endorsement, back dead book learning education environment, which led to the schooling is poor overall quality of students is not high defects. Admittedly, traditional education students in basic education has played a role, but this method of education does not meet the current needs of higher education, many students under the guidance of this education became dead reading, reading books dead nerd . In this regard, we must establish a new educational ideas and concepts with contemporary social development to adapt to scientific and cultural quality as the basis, the core of ideological and moral qualities, professional skills, quality as the backbone for the protection of physical and mental quality, comprehensive structure Students the new system of quality education, strive to cultivate the ground to explore, will learn, good thinking, college student can create.

The nature of university education is to train personnel, teachers and students are the main body, 
educators and the educated are essential factors that constitute two different universities, are indispensable, no teacher schools can not be called the school, and teachers Quality directly determines the level of the students trained quality level, therefore, depends directly on whether students excellent teachers is excellent. A lot of experience leading universities showed excellent teacher's role not only in the students' academic guidance, but also in their dedication to the cause of education, science, truth pursuit and rigorous teaching style, science teaching method. Teachers will determine whether the strong whether a school with core competitiveness, high-quality team of teachers trained more excellent, innovative high-quality talent, which is why many colleges are competing for highly qualified teachers, they build a strong faculty as the university's top priority. Teachers decide whether education is excellent success, but many teachers already forgotten the real purpose of teaching, teaching them not to seek a breakthrough, just like duck fill impart knowledge to students, in their eyes, teaching is not the wisdom of enlightenment, but mechanically remember conclusion, stylized instill knowledge. They not only lack of spiritual teachers have first-class pursuit of science, innovation, and the lack of that discovery, training, support outstanding students as teachers vocation teacher culture. Have to admit, there is a huge gap between Chinese universities and world-class universities now, but a large part of this gap because the gap between teachers, in particular in: poor teaching style and the style of study, the lack of academic leaders, educational philosophy behind the teachers' professional level is not high, teachers and personnel system inflexible, difficult to attract and retain quality teachers, and so on. Training the innovative talents of the teacher's role is irreplaceable, and the University else who has a master of that sense of loss also.

\section{Conclusion}

Our education system has a lot of drawbacks, so many people recommend the introduction of foreign institutional mechanisms for education and training, but in the middle, there are many needs rectification, then the application, there is a market in order to survive, it needs only requirements. This is the road, China's education is not part of people, nor is it a generation thing, it needs to go after another trying to do. The so-called \$ decade sterile tree, a hundred years educating people, to cultivate innovative talents is the same, whether it is a teacher or social policy makers should be secure enough for innovative teaching practice, we must consciously develop students' ability to innovate, for example, in the case of conditions can allow students to drop out entrepreneurship, select outstanding students study abroad and learn foreign advanced learning methods to encourage students published in the official journal, some institutions can establish some students open laboratory encourage students to dare to practice, to carry out outstanding innovation Awards, to have outstanding achievements in extracurricular activities or athletics competitions give students some material or spiritual reward, to cultivate students 'innovative spirit, to improve students' creativity as an evaluation and colleges an important part of the students, the only way to cultivate more excellent high-quality personnel for socialist modernization drive train more reserve personnel.

\section{References}

[1] Su Ming, School is Famous for Famous Teachers [J]. China Education Daily, 2005, 3, 15.

[2] Yu Wenshu. In the instrument. Cultivate all-round development of trust [J]. China Education Daily, 2003, 1, 16.

[3] Gao Xiang, Jiang Daojun. Times, Yang Sciences, Humanities and gale [J]. China Education Daily, 2003, 3, 25.

[4] Zhang Dexiang. Well - Social Innovation in Education [J]. China Education Daily, 2003, 3, 16. 